\title{
Utilização de fitoterápicos nas unidades básicas de atenção à saúde da família no município de Maracanaú (CE)
}

\author{
Maria Izabel G. Silva ${ }^{1 *}$, Ana Paula S. Gondim², Ila Fernanda S. Nunes ${ }^{3}$, \\ Francisca Cléa F. Sousa
}

\author{
${ }^{1}$ Laboratório de Neurofarmacologia, Departamento de Fisiologia e Farmacologia, Faculdade de Medicina, \\ Universidade Federal do Ceará, Rua Coronel Nunes de Melo, 1127, Porangabussu, 60430-270, Fortaleza, Ceará, \\ Brasil, \\ ${ }^{2}$ Curso de Farmácia, Centro de Ciências da Saúde, Universidade de Fortaleza, Av. Washington Soares, $N^{o} 1321$, \\ Bairro Edson Queiroz, CEP 60.811.905, Fortaleza, Ceará, Brasil, \\ ${ }^{3}$ Laboratório de Doenças Infecciosas, Departamento de Fisiologia e Farmacologia, Faculdade de Medicina, \\ Universidade Federal do Ceará, Rua Coronel Nunes de Melo, 1315, Porangabussu, 60430-270, Fortaleza, Ceará, \\ Brasil
}

\begin{abstract}
RESUMO: Diante da deficiente assistência farmacêutica brasileira, alguns estados no país vêm realizando a implantação de Programas de Fitoterapia na atenção primária à saúde. Com o objetivo de conhecer o perfil de utilização e prescrição dos fitoterápicos desenvolvidos no município de Maracanaú (CE), foram entrevistados 226 pacientes atendidos nas Unidades de Saúde da Família, cujas prescrições medicamentosas continham fitoterápicos. A prevalência de fitoterápicos nas prescrições foi de $20,6 \%$. Nestas, foram encontrados 10 dentre os 15 fitoterápicos produzidas no município, entre cápsulas, pomadas, géis, tinturas e xarope. As principais indicações terapêuticas dos fitoterápicos foram para as afecções respiratórias, cutâneas e para o diabetes mellitus. Observouse, desta forma, um cenário favorável ao Programa Farmácias Vivas de Maracanaú. No entanto, vale ressaltar que estudos posteriores se tornam necessários para garantir o controle de qualidade, bem como a eficácia e segurança dos fitoterápicos.
\end{abstract}

Unitermos: Fitoterápicos, prescrição medicamentosa, saúde da família.

\begin{abstract}
The use of herbal medicines in the family health care units in Maracanaú (CE)". Currently in Brazil, some herbal therapy programs are being developed in primary healthcare services to supply the communities lacking basic medicines. To investigate the use and prescription of herbal medicines in the city of Maracanú, State of Ceará, Brazil, 226 patients with prescriptions containing herbal medicine were interviewed in Family Health Care Units and their drugs prescription were analyzed. The prevalence of herbal medicines in the prescription was $20.6 \%$. Among the 15 herbal medicines produced in city, 10 were among the prescriptions reviewed, such as capsules, ointments, gels, dyes and syrup. The herbal medicines were mainly indicated for the treatment of respiratory problems skin conditions, and diabetes mellitus. Data support the use of herbal therapy in primary health care in Maracanaú. However, it is important to emphasize that there is a need to conduct further study on the efficacy and safety of these herbal medicines, as well as on their quality control.
\end{abstract}

Keywords: Herbal drugs, drugs prescription, family health.

\section{INTRODUÇÃO}

O sistema público de saúde no Brasil não possui uma política de assistência farmacêutica capaz de suprir as necessidades medicamentosas da população, sobretudo no nordeste brasileiro, onde a população carente apresenta dificuldades para obter os medicamentos essenciais, bem como adoece muito mais (Cosendey et al., 2000; Matos, 1998). Com a descentralização do poder público, atualmente em nosso país, o município atinge a gestão plena, com autonomia para implantar programas de assistência à saúde, quando necessários (Vianna et al.,
2002; Vianna e Dal Poz, 1998). Desta forma, alguns estados e municípios brasileiros vêm realizando nas duas últimas décadas a implantação de Programas de Fitoterapia na atenção primária à saúde, com o intuito de suprir as carências medicamentosas de suas comunidades. (Ogava et al., 2003; Michilis, 2004). Considerando que grande parte da cobertura da atenção primária no Brasil é realizada mediante o Programa Saúde da Família (PSF), através das Unidades de Atenção Básicas, muitos dos programas de fitoterapia desenvolvidos no sistema público de saúde estão, atualmente, vinculados ao PSF.

A experiência mais antiga que influenciou 
a criação de programas de fitoterapia no Brasil foi o Programa Farmácias Vivas, criado pelo professor Francisco José de Abreu Matos da Universidade Federal do Ceará, há mais de vinte anos. É o primeiro programa de assistência social farmacêutica baseado no emprego científico de plantas medicinais desenvolvido no Brasil, tendo por objetivo produzir medicamentos fitoterápicos acessíveis à população carente (Matos, 1998). Após a sua criação no estado do Ceará, tornou-se referência para o do Nordeste brasileiro e, posteriormente, para todo o país (Malta et. al., 1999).

O município de Maracanaú (CE) foi o primeiro a implantar o Programa Farmácias Vivas no sistema público de Saúde. Atualmente, o programa está vinculado à Secretaria Municipal de Saúde e tem se destacado pela organização, abrangência e funcionalidade. Sua estrutura básica é composta por 01 horto com 40 canteiros, para o cultivo das plantas medicinais, e 01 laboratório de manipulação, para a produção dos medicamentos fitoterápicos. A dispensação dos produtos à comunidade ocorre nas Unidades Básicas de Atenção à Saúde da Família (UBASF) do PSF, mediante prescrição medicamentosa do profissional de saúde.

Assim, o presente trabalho teve como objetivo conhecer os fitoterápicos produzidos em Maracanaú e descrever o perfil de utilização e prescrição desses medicamentos nas UBASF selecionadas para o estudo.

\section{MATERIAL E MÉTODOS}

O presente trabalho foi realizado no município de Maracanaú-CE, localizado a $19 \mathrm{Km}$ da capital Fortaleza, entre os meses de agosto e setembro de 2002. Para a identificação dos medicamentos fitoterápicos produzidos pelo Programa Farmácias Vivas, foi realizado um levantamento de dados no Memento Farmacêutico formulado para este programa pela Secretaria Municipal de Saúde (Andrade, 2000). Neste levantamento, foram coletadas as seguintes informações referentes aos fitoterápicos: as plantas medicinais utilizadas na produção, suas ações farmacológicas, indicações terapêuticas, apresentações e formas de administração.

Até a data do estudo, a administração do PSF de Maracanaú era realizada através de seis (06) Áreas de Vigilância de Saúde (AVISA). Cada AVISA era responsável pela administração de um número variável de UBASF, que totalizavam 17 unidades em todo o município. Para a obtenção de uma amostra aleatória estratificada por área geográfica, foram selecionadas, randomicamente, $01 \mathrm{UBASF}$ de cada AVISA, totalizando 06 UBASF selecionadas.

Durante o período do estudo, foram quantificadas todas as prescrições medicamentosas de pacientes atendidos nas UBASF selecionadas com idade igual ou superior a 18 anos, para a determinação da prevalência dos fitoterápicos prescritos. Dentre o total de prescrições, foram selecionadas para o estudo aquelas que continham pelo menos um (01) medicamento fitoterápico. A coleta dos dados referentes ao perfil dos usuários foi realizada mediante entrevista direta com os pacientes que tiveram suas prescrições selecionadas para o estudo. Para tanto, foi utilizado um questionário estruturado contendo perguntas fechadas, referentes às variáveis de sexo, idade e escolaridade. Todos os entrevistados foram previamente esclarecidos a respeito do conteúdo e objetivo das entrevistas e concordaram em colaborar com o estudo. As entrevistas foram realizadas após os pacientes adquirirem os fitoterápicos nas farmácias das UBASF. As frequências dos fitoterápicos prescritos e suas respectivas indicações terapêuticas foram obtidas mediante a análise das prescrições e prontuários dos pacientes selecionados.

Os dados obtidos foram inseridos em um banco de dados e analisados com o auxílio do software Epi-Info vs. 6.04. A análise quantitativa dos dados foi realizada mediante distribuições de freqüências, cálculos de médias e desvios-padrão, e o teste $t$ de Student.

\section{RESULTADOS}

Mediante análise do Memento Farmacêutico do Programa Farmácias Vivas de Maracanaú, constatouse que o laboratório de manipulação produz 15 especialidades fitoterápicas. Na Tabela 1, estão descritas as características terapêuticas de cada fitoterápico. Durante o período de realização do estudo, não estavam sendo produzidos as Cápsulas de Maracujá e de Hortelã Rasteira e a Hortelã Rasteira Gotas, devido à carência de recursos da Farmácia Viva (Tabela 1).

Durante a realização deste trabalho, foram registradas 1.095 prescrições de pacientes maiores ou igual a 18 anos nas UBAF selecionadas. Dentre esse total, $226(20,6 \%)$ pacientes apresentaram prescrições contendo pelo menos 01 medicamento fitoterápico. Observou-se que $85,4 \%$ (193/226) dos pacientes entrevistados foram do sexo feminino. Com relação à idade desses pacientes, registrou-se uma média de 38 anos $\pm 16,18$, obtendose uma diferença estatisticamente significante $(p<0,05)$ entre a média de idade dos pacientes de diferentes sexos $(44,85 \pm 16,44$ para o masculino e $36,93 \pm 15,90$ para o feminino) . No que se refere ao nível de escolaridade, a grande maioria dos pacientes $(75,7 \%-171 / 226)$ cursaram apenas o ensino fundamental (Tabela 2).

Nas prescrições analisadas foram encontrados 542 medicamentos, com uma média de 2,39 medicamentos por prescrição. Dentre estes, 229 (41,7\%) foram fitoterápicos e 313 (58,3\%) alopáticos. Observouse médias de 1,38 e 1,01 medicamentos alopáticos e fitoterápicos por prescrição, respectivamente (Tabela 3).

Dentre os 15 tipos de medicamentos fitoterápicos produzidos em Maracanaú, 10 foram encontrados nas prescrições analisadas. Observou-se uma predominância do Xarope Expectorante (composto por Guaco e Malvariço), que correspondeu a 63,8\% (146/229) de todos os fitoterápicos prescritos. O Sabonete de Alecrim 
Tabela 1. Medicamentos Fitoterápicos produzidos em Maracanaú: plantas utilizadas, partes usadas, ações macológicas, indicações terapêuticas, apresentações e formas de administrações - Maracanaú (Ce), Agosto-Setembro/2002.

\begin{tabular}{|c|c|c|c|c|c|c|}
\hline $\begin{array}{l}\text { Produto } \\
\text { Fitoterápico }\end{array}$ & Planta Utilizada & $\begin{array}{l}\text { Parte } \\
\text { Utilizada }\end{array}$ & $\begin{array}{l}\text { Ação } \\
\text { Farmacológica }\end{array}$ & $\begin{array}{l}\text { Indicação } \\
\text { Terapêutica }\end{array}$ & Apresentação & Administração \\
\hline $\begin{array}{l}\text { Antisséptico } \\
\text { Bucal } \\
\text { (uso externo) }\end{array}$ & $\begin{array}{l}\text { - Alecrim } \\
\text { Pimenta } \\
\text { (Lippia sidoides } \\
\text { C.) } \\
\text { - Alfavaca } \\
\text { (Ocimum } \\
\text { gratissimum L.) }\end{array}$ & Folhas & Antisséptico & $\begin{array}{l}\text { Aftas, mau } \\
\text { hálito, } \\
\text { inflamações } \\
\text { da boca e } \\
\text { garganta. }\end{array}$ & $\begin{array}{l}\text { Frasco de } \\
60 \mathrm{ml}\end{array}$ & $\begin{array}{l}\text { Diluir } 1 \text { colher de sopa } \\
\text { em } 1 / 2 \text { copo de água, } \\
\text { fazer bochechos e } \\
\text { gargarejos }\end{array}$ \\
\hline $\begin{array}{l}\text { Cápsulas de } \\
\text { Maracujá } \\
\text { (uso interno) }\end{array}$ & $\begin{array}{l}\text { - Maracujá } \\
\text { (Passiflora } \\
\text { edulis } \\
\text { Sims) }\end{array}$ & Folhas & Calmante & $\begin{array}{l}\text { Irritações e } \\
\text { insônia }\end{array}$ & $\begin{array}{l}\text { Frasco com } 20 \\
\text { cápsulas }\end{array}$ & $\begin{array}{l}02 \text { cápsulas de } \\
\text { preferência à noite }\end{array}$ \\
\hline $\begin{array}{l}\text { Creme Vaginal } \\
\text { de Aroeira } \\
\text { (uso externo) }\end{array}$ & $\begin{array}{l}\text { - Aroeira } \\
\text { (Miracrodruon } \\
\text { urundeuva } \\
\text { Fr.All) }\end{array}$ & $\begin{array}{l}\text { Entre- } \\
\text { casca }\end{array}$ & $\begin{array}{l}\text { Antiinflamatório } \\
\text { e cicatrizante }\end{array}$ & $\begin{array}{l}\text { Inflamações } \\
\text { ginecológicas }\end{array}$ & $\begin{array}{l}\text { Bisnaga de } \\
50 \mathrm{~g}+ \\
\text { aplicador }\end{array}$ & A critério médico \\
\hline $\begin{array}{l}\text { Elixir de } \\
\text { Aroeira } \\
\text { (uso interno) }\end{array}$ & $\begin{array}{l}\text { - Aroeira } \\
\text { (Miracrodruon } \\
\text { urundeuva } \\
\text { Fr.All) }\end{array}$ & $\begin{array}{l}\text { Entre- } \\
\text { casca }\end{array}$ & $\begin{array}{l}\text { Antihistamínica } \\
\text { e } \\
\text { antibradicinínica }\end{array}$ & $\begin{array}{l}\text { Gastrite e } \\
\text { ulcera gástrica }\end{array}$ & $\begin{array}{l}\text { Frasco de } \\
100 \mathrm{ml}\end{array}$ & $\begin{array}{l}1 \text { colher de sobremesa } \\
03 \text { vezes ao dia }\end{array}$ \\
\hline $\begin{array}{l}\text { Gotas } \\
\text { Estomacais } \\
\text { (uso interno) }\end{array}$ & $\begin{array}{l}\text { - Malva Santa } \\
\text { (Plectranthus } \\
\text { barbatus Andr.) }\end{array}$ & Folhas & $\begin{array}{l}\text { Estomáquico, } \\
\text { hipossecretor } \\
\text { gástrico }\end{array}$ & $\begin{array}{l}\text { Azia, má } \\
\text { digestão e } \\
\text { ressaca }\end{array}$ & $\begin{array}{l}\text { Frasco conta- } \\
\text { gotas de } 30 \mathrm{ml}\end{array}$ & $\begin{array}{l}20 \text { a } 40 \text { gotas na hora } \\
\text { do incômodo o ate } 3 \\
\text { vezes ao dia }\end{array}$ \\
\hline $\begin{array}{l}\text { Hortelã } \\
\text { Rasteira } \\
\text { Cápsulas } \\
\text { (uso interno) }\end{array}$ & $\begin{array}{l}\text { - Hortelã Rasteira } \\
\text { (Mentha villosa } \\
\text { Huds) }\end{array}$ & Folhas & $\begin{array}{l}\text { Amebicida e } \\
\text { giardicida }\end{array}$ & $\begin{array}{l}\text { Amebíase e } \\
\text { giardíase }\end{array}$ & $\begin{array}{l}\text { Envelope com } \\
30 \text { cap. de } \\
250 \mathrm{mg}\end{array}$ & $\begin{array}{l}\text { Até } 12 \mathrm{a}: 3 \text { cáp/dia }-5 \mathrm{~d} \\
\text { Adultos: } 6 \text { cáp/dia }-5 \mathrm{~d} \\
\text { Obs: repetir após } 10 \mathrm{~d}\end{array}$ \\
\hline $\begin{array}{l}\text { Hortelã } \\
\text { Rasteira Gotas } \\
\text { (uso interno) }\end{array}$ & $\begin{array}{l}\text { - Hortelã Rasteira } \\
\text { (Mentha villosa } \\
\text { Huds) }\end{array}$ & Folhas & $\begin{array}{l}\text { Amebicida e } \\
\text { giardicida }\end{array}$ & $\begin{array}{l}\text { Amebíase e } \\
\text { giardíase }\end{array}$ & $\begin{array}{l}\text { Frasco conta- } \\
\text { gotas de } 30 \mathrm{ml}\end{array}$ & $\begin{array}{l}\text { Criança: } 25 \text { gts } 3 x \text { dia- } 5 \mathrm{~d} \\
\text { Adulto: } 50 \text { gts } 3 \mathrm{x} \text { dia- } \\
5 \mathrm{~d} \\
\text { Obs: repetir após } 10 \mathrm{~d}\end{array}$ \\
\hline $\begin{array}{l}\text { Mastruço Gel } \\
10 \% \text { (uso } \\
\text { externo }\end{array}$ & $\begin{array}{l}\text { - Mastruço } \\
\text { (Chenopodium } \\
\text { ambrosioides L.) }\end{array}$ & Folhas & Antiinflamatório & $\begin{array}{l}\text { Tombos e } \\
\text { luxações }\end{array}$ & $\begin{array}{l}\text { Pote com } 30 \\
\text { grs }\end{array}$ & $\begin{array}{l}\text { Massagem suave sobre } \\
\text { a região afetada }\end{array}$ \\
\hline $\begin{array}{l}\text { Mentrasto } \\
\text { Cápsulas } \\
\text { (uso interno) }\end{array}$ & $\begin{array}{l}\text { - Mentrasto } \\
\text { (Ageratum } \\
\text { conyzoides L.) }\end{array}$ & Folhas & $\begin{array}{l}\text { Antiinflamatório } \\
\text { e analgésico }\end{array}$ & $\begin{array}{l}\text { Artrite, artrose, } \\
\text { analgesia, cóli- } \\
\text { cas menstruais, } \\
\text { inflamações } \\
\text { dentárias }\end{array}$ & $\begin{array}{l}\text { Pote com } 20 \\
\text { cápsulas }\end{array}$ & 02 a 06 cápsulas ao dia \\
\hline $\begin{array}{l}\text { Pomada } \\
\text { cicatri- } \\
\text { zante de } \\
\text { Confrei } \\
\text { (uso externo) }\end{array}$ & $\begin{array}{l}\text { - Confrei } \\
\text { ( Symphytum } \\
\text { officinale) }\end{array}$ & Folhas & $\begin{array}{l}\text { Cicatrizante, } \\
\text { anti- } \\
\text { irritante, } \\
\text { hidratante } \\
\text { e removedor } \\
\text { de tecido } \\
\text { necrosado }\end{array}$ & $\begin{array}{l}\text { Ferimentos, } \\
\text { queimaduras, } \\
\text { úlcera varicosa }\end{array}$ & $\begin{array}{l}\text { Pote com } 30 \\
\text { grs }\end{array}$ & $\begin{array}{l}\text { Aplicar } 1 \text { a } 2 \text { vezes ao } \\
\text { dia na região afetada }\end{array}$ \\
\hline $\begin{array}{l}\text { Romã Gel } \\
\text { (uso externo) }\end{array}$ & $\begin{array}{l}\cdot \text { Romã (Punica } \\
\text { granatum L.) }\end{array}$ & $\begin{array}{l}\text { Casca } \\
\text { do } \\
\text { fruto }\end{array}$ & Antivirótica & Herpes e aftas & $\begin{array}{l}\text { Pote com } 30 \\
\text { grs } \\
\text { Gel a } 10 \%\end{array}$ & $\begin{array}{l}\text { Massagear o local } \\
\text { afetado }\end{array}$ \\
\hline \multirow[t]{2}{*}{$\begin{array}{l}\text { Tintura de } \\
\text { Alecrim } \\
\text { Pimenta } \\
\text { (uso interno) }\end{array}$} & $\begin{array}{l}\text { Alecrim Pimenta } \\
\text { (Lippia sidoides } \\
\text { C) }\end{array}$ & Folhas & Antisséptico & $\begin{array}{l}\text { Antissepsia } \\
\text { (pele, garganta) } \\
\text { e compressas }\end{array}$ & $\begin{array}{l}\text { Frasco de } \\
60 \mathrm{ml}\end{array}$ & $\begin{array}{l}\text { Aplicação direta ou } \\
\text { gargarejos ( } 1 \text { parte } \\
\text { para } 2 \text { de água). }\end{array}$ \\
\hline & & & & & & $\begin{array}{r}\text { Rev. Bras. Farmacogn. } \\
\text { Braz J. Pharmacogn. } \\
\text { 16(4):out/dez. } 2006\end{array}$ \\
\hline
\end{tabular}




\begin{tabular}{|c|c|c|c|c|c|c|}
\hline $\begin{array}{l}\text { Tintura de } \\
\text { Mororó Gotas } \\
\text { (uso interno) }\end{array}$ & $\begin{array}{l}\text { - Mororó } \\
\text { (Bauhinia } \\
\text { forficata L.) }\end{array}$ & Folhas & Hipoglicemiante & $\begin{array}{l}\text { Hipoglicemiante } \\
\text { na Diabetes }\end{array}$ & $\begin{array}{l}\text { Frasco de } \\
30 \mathrm{ml}\end{array}$ & $\begin{array}{l}30 \text { gts em jejum, com } \\
\text { acompanhamento } \\
\text { médico. }\end{array}$ \\
\hline $\begin{array}{l}\text { Tintura de } \\
\text { Torém Gotas } \\
\text { (interno) }\end{array}$ & $\begin{array}{l}\text { - Torém } \\
\text { (Cecropia } \mathrm{spp})\end{array}$ & Folhas & $\begin{array}{l}\text { Antihipertensivo } \\
\text { e diurético }\end{array}$ & Hipertensão & $\begin{array}{l}\text { Frasco de } \\
30 \mathrm{ml}\end{array}$ & $\begin{array}{l}30 \text { gts em jejum, com } \\
\text { acompanhamento méd. }\end{array}$ \\
\hline $\begin{array}{l}\text { Xarope } \\
\text { expectorante } \\
\text { (uso interno) }\end{array}$ & $\begin{array}{l}\text {-Guaco (Mikania } \\
\text { glomerata } \\
\text { Spreng) } \\
\text {-Malvariço } \\
\text { (Plectrantus } \\
\text { amboinicus } \\
\text { Lour) }\end{array}$ & Folhas & $\begin{array}{l}\text { Expectorante e } \\
\text { broncodilatador }\end{array}$ & $\begin{array}{l}\text { Bronquite, } \\
\text { gripes, } \\
\text { resfriados e } \\
\text { asma }\end{array}$ & $\begin{array}{l}\text { Frasco de } \\
100 \mathrm{ml}\end{array}$ & $\begin{array}{l}\text { Crianças: } 1 \text { colher de } \\
\text { sobremesa } 3 \text { a } 4 \mathrm{X} / \text { dia } \\
\text { Adulto: } 1 \text { colher de } \\
\text { sopa } 3 \text { a } 4 \mathrm{X} / \text { dia }\end{array}$ \\
\hline
\end{tabular}

Fonte: Memento Farmacêutico, Prefeitura Municipal de Maracanaú, Secretaria de Saúde-Setor de Assistência Farmacêutica - 2000 .

Tabela 2. Distribuição dos pacientes selecionados para o estudo em função do sexo e escolaridade - Maracanaú (Ce), Agosto - Setembro/2002.

\begin{tabular}{lcc}
\hline Características dos Pacientes Entrevistados $^{\text {a }}$ & $\begin{array}{c}\text { Freqüência } \\
\text { n (226) }\end{array}$ & $\begin{array}{c}\text { Percentual } \\
\%(100)\end{array}$ \\
\hline Sexo & 33 & 14,6 \\
Masculino $^{\text {b }}$ & 193 & 85,4 \\
$\quad \begin{array}{l}\text { Feminino }^{c} \\
\text { Escolaridade }\end{array} \quad$ & - & - \\
$\quad$ Curso superior & 33 & 14,6 \\
$\quad$ Ensino médio & 171 & 75,7 \\
$\quad$ Ensino Fundamental & 22 & 9,7 \\
$\quad$ Nunca freqüentaram a escola
\end{tabular}

a A idade média dos pacientes foi de 38 anos $\pm 16,18$. A idade média para os pacientes do sexo masculino ${ }^{\mathrm{b}}$ foi de 44 , $85 \pm 16,44$, enquanto que para o sexo feminino ${ }^{c}$ foi de $36,93 \pm 15,90(p<0,05)$.

e a Tintura de Mororó estiveram presentes (cada um) em $11,4 \%$ (26/229) das prescrições. Os 24,8\% (57/229) restantes, bem como suas respectivas indicações terapêuticas encontram-se descritas na tabela 4 .

\section{DISCUSSÃO}

O município de Maracanaú, através do Programa Farmácias Vivas, produz 15 tipos de medicamentos fitoterápicos. De acordo com a legislação em vigor no país, que regulamenta o registro de medicamentos fitoterápicos, se faz necessário a garantia da qualidade, eficácia e segurança de tais produtos para o consumidor. No entanto, a Agência Nacional de Vigilância Sanitária (ANVISA) reconhece, dentro daqueles fitoterápicos com maior número de estudos científicos, uma lista de drogas vegetais que têm a permissão de obter o registro simplificado pela indústria (Brasil, 2004a), não havendo necessidade de validar as indicações terapêuticas e segurança de uso (Ribeiro et al., 2005). Dentre os 15 fitoterápicos produzidos em Maracanaú, apenas 3 deles, o Xarope Expectorante (composto por Guaco e Malvariço), a Pomada de Confrei e as Cápsulas de Maracujá, contêm espécies vegetais presentes na lista da ANVISA, que

16(4):out/dez. 2006 
prescrições contendo medicamento fitoterápico, a maioria foi do sexo feminino $(85,4 \%)$, com média de idade inferior à do sexo masculino. Diversos estudos demonstram o predomínio do sexo feminino no consumo de medicamentos provenientes tanto da medicina convencional (Bertoldi et al., 2004), como da complementar (Sanfélix et al., 2001). De acordo com Sanfélix et al. (1999), as variáveis que determinam o número de medicamentos consumidos são os problemas de saúde e a freqüência de busca por atendimento médico. Concepções sócio-culturais impõem ao homem não ser facultado definir-se como doente, o que o leva a postergar a busca por atendimento médico, enquanto as mulheres são consideradas mais frágeis e susceptíveis às doenças, e, portanto, buscam atendimento médico com maior freqüência, o que as tornam mais vulneráveis aos riscos da utilização de medicamentos, sejam eles alopáticos ou fitoterápicos (Leite, 2000).

A maioria dos entrevistados cursou apenas o ensino fundamental e nenhum deles possuía curso superior. Estudos realizados em países de primeiro mundo, demonstram uma prevalência do uso de fitoterápicos (Harnack et al., 2001) e outras terapias complementares (Astin, 1998) entre indivíduos com alto nível de escolaridade e renda, o que também tem sido observado nos últimos anos em países em desenvolvimento como o Brasil (Ribeiro et al., 2005). No entanto, a divergência em nossos resultados se justifica diante do fato de que a nossa amostra consiste em pacientes que buscam o sistema público de saúde e, portanto, possuem menor nível de escolaridade e renda, como observado por Dias da Costa e Facchini (1997). Desta forma, é pertinente ressaltar que o perfil dos pacientes demonstrado neste estudo não corresponde aos indivíduos que buscam medicamentos fitoterápicos por iniciativa própria, mas, àqueles que utilizam um serviço público no qual lhes são disponibilizados tais medicamentos.

A média de medicamentos por prescrição, entre alopáticos e fitoterápicos, encontrada no presente estudo foi de $\chi=2,39$. Estudos de utilização de medicamentos em serviços públicos de saúde que consideram apenas medicamentos alopáticos, revelam resultados semelhantes (Silva et al., 2000). Entretanto, vale ressaltar que, nas prescrições analisadas em nosso estudo, estavam incluídos tanto medicamentos fitoterápicos $(\chi=1,01)$, como alopáticos $(\chi=1,38)$, sugerindo uma equivalência quantitativa entre ambos, quando prescritos concomitantemente.

Dentre os fitoterápicos encontrados nas prescrições, houve uma predominância do Xarope Expectorante $(63,8 \%)$, indicado para afecções respiratórias. Estudos realizados em diversos lugares do mundo apontam as afecções respiratórias como uma das causas mais freqüentes para o uso dos medicamentos

Tabela 3. Quantidade de medicamentos alopáticos e fitoterápicos identificados nas prescrições dos pacientes entrevistados - Maracanaú (Ce), Agosto - Setembro/2002.

\begin{tabular}{lccc}
\hline Medicamentos Prescritos $^{\text {a }}$ & $\begin{array}{c}\text { Freqüência } \\
\text { Medicamento Alopático }\end{array}$ & $\begin{array}{c}\text { Percentual } \\
\%\end{array}$ & Média \\
\hline Medicamento Fitoterápico & 313 & 58,3 & 1,38 \\
\hline Total & 229 & 41,7 & 1,01 \\
\hline
\end{tabular}

a A média de medicamentos por prescrição foi de 2,39.

Tabela 4. Distribuição dos medicamentos fitoterápicos encontrados nas 226 prescrições analisadas em função da indicação terapêutica - Maracanaú (Ce), Agosto-Setembro/2002.

\begin{tabular}{llcc}
\hline Medicamentos Fitoterápicos & Indicação Terapêutica & Freqüência & \multicolumn{2}{c}{ Percentual } \\
& & 146 & 63,8 \\
\hline Xarope Expectorante & Afecções respiratórias & 26 & 11,4 \\
Sabonete de Alecrim & Afecções cutâneas & 26 & 11,4 \\
Tintura de Mororó & Diabetes & 9 & 3,9 \\
Pomada de Confrei & Afecções cutâneas & 8 & 3,5 \\
Cápsula de Mentrasto & Dores musculares & 5 & 2,2 \\
Antisséptico Bucal & Transtornos gastrintestinais & 3 & 1,3 \\
Creme de Aroeira & Afecções geniturinárias & 3 & 1,3 \\
Gotas Estomacais & Transtornos gastrintestinais & 2 & 0,8 \\
Elixir de Aroeira & Transtornos gastrintestinais & 1 & 0,4 \\
Tintura de Torém & Hipertensão & $229 *$ & 100 \\
\hline Total & & \multicolumn{2}{c}{} \\
\hline
\end{tabular}

* Em três prescrições foram encontrados dois medicamentos fitoterápicos, as demais continham apenas um.

\begin{tabular}{r|c}
\hline Rev. Bras. Farmacogn. & 459 \\
Braz J. Pharmacogn. & $45(4)$ :out/dez. 2006
\end{tabular}




\title{
ANEXO I
}

\author{
UNIVERSIDADE FEDERAL DO CEARÁ \\ MESTRADO EM CIÊNCIAS FARMACÊUTICAS
}

DISSETAÇÃO DE MESTRADO: UTILIZAÇÃO DE FITOTERÁPICOS NAS UNIDADES BÁSICAS DE SAÚDE DA FAMÍLIA (UBSF) NO MUNICÍPIO DE MARACANAÚ - CE
QUESTIONARIO PARA REGISTRO DO USUÁRIO E DE SUAS PRESCRIÇÕES NAS UBASF
Data: UBSF:
No Identificação:

PARTE A - DADOS DO PACIENTE

\begin{tabular}{|c|c|}
\hline 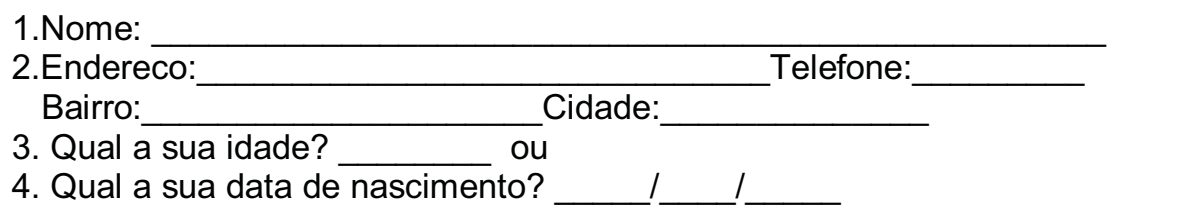 & $\begin{array}{l}\text { Compl.: } \\
\text { Idade: } \\
\text { Nas:_L_L_ }\end{array}$ \\
\hline $\begin{array}{l}\text { 5. Até que série o } \operatorname{Sr}(\mathrm{a}) \text { estudou na escola? } \\
\text { Série do _ Grau Nunca estudou=5 }\end{array}$ & Escola: \\
\hline $\begin{array}{l}\text { 6. O médico passou algum remédio feito de planta medicinal para o } \operatorname{Sr}(\mathrm{a}) \text { ? } \\
\begin{array}{ll}\text { 1= Sim } \quad \mathbf{2 =} \text { Não } & 3=\text { Outros } \\
\text { 6.1. Se sim, qual? }\end{array}\end{array}$ & Planta: \\
\hline 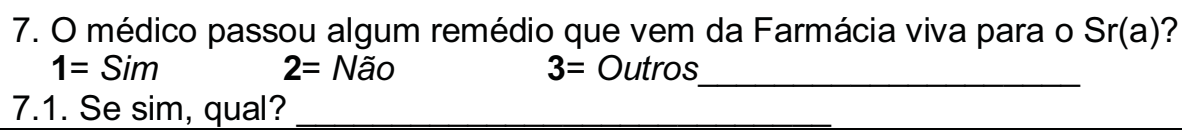 & F.viva: \\
\hline 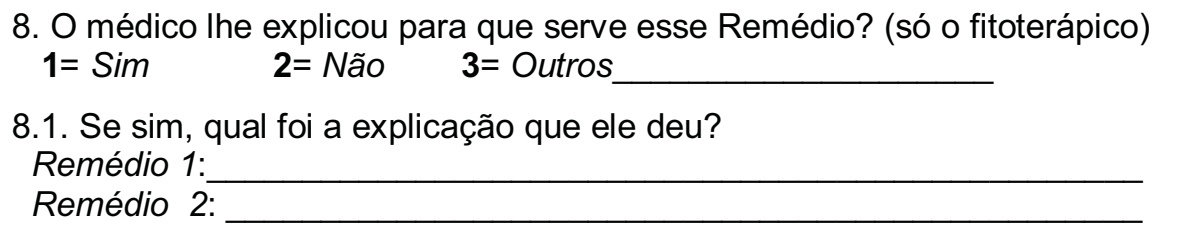 & Serve: \\
\hline $\begin{array}{l}\text { 9. O } \operatorname{Sr}(a) \text { já conhecia esse remédio antes do médico passar? } \\
\begin{array}{lll}\mathbf{1}=\operatorname{Sim} & \mathbf{2}=\text { Não } \quad 3=\text { Outros }\end{array}\end{array}$ & Explicou: \\
\hline $\begin{array}{l}\text { 10. O Sr(a) já usou este Remédio antes? (para aqueles que sabiam que } \\
\text { estavam recebendo "remédio feito de planta") } \\
\begin{array}{l}\text { 1= Sim } \quad 2=\text { Não } \quad 3=\text { Outros } \\
\text { 10.1. Se sim, há quanto tempo usa? }\end{array}\end{array}$ & Usou: \\
\hline 11.O que o $\mathrm{Sr}(\mathrm{a})$ tem a dizer sobre esse remédio? & \\
\hline
\end{tabular}


PARTE B - DADOS DA PRESCRIÇÃO

\begin{tabular}{|l|l|l|l|l|}
\hline 12. Medicamento & $\begin{array}{l}\text { 13.Via de adminis- } \\
\text { tração }\end{array}$ & 14. Posologia & 15. Quantidade & $\begin{array}{l}\text { 16.Duração do } \\
\text { tratamento }\end{array}$ \\
\hline & & & & \\
\hline & & & & \\
\hline & & & & \\
\hline & & & & \\
\hline & & & & \\
\hline & & & & \\
\hline & & & & \\
\hline & & & & \\
\hline & & & & \\
\hline 17. Diagnóstico provável: & & & \\
\hline
\end{tabular}

Obs.: Apenas parte dos dados obtidos com a aplicação deste questionário foram descritos no presente artigo.

fitoterápicos, os quais estão relacionados com o tratamento de quadros menores (Sanfélix et al., 2001). O elevado número de prescrições contendo o Xarope Expectorante pode ser explicado, em parte, devido à alta freqüência de afecções respiratórias registradas nas UBASF no período de realização do estudo (dados não mostrados). Por outro lado, é possível que os profissionais de saúde responsáveis por tais prescrições debitem alta credibilidade na eficiência terapêutica daquele xarope, uma vez que, em trabalho anterior nós demonstramos que mais de $90 \%$ de seus usuários relataram êxito terapêutico (Silva et al., 2005). Um outro estudo, de cunho qualitativo, realizado por Silva (2003), demonstrou uma adesão e aceitação da fitoterapia por parte dos profissionais de saúde de Maracanaú superior a $90 \%$.

A Tintura de Mororó, indicado para o diabetes mellitus, foi o segundo fitoterápico mais prescrito, juntamente com o Sabonete de Alecrim, indicado para diversas formas de afecções cutâneas. Observou-se que mais da metade das prescrições que continham a Tintura de Mororó (Bauhinia forficata L) também continham uma medicação alopática hipoglicemiante, enquanto nas demais prescrições a tintura foi prescrita isoladamente (dados não mostrados). Alguns estudos sobre plantas do gênero Bauhinia (B. manca, B. rufescens, B. forficata, $B$. candicans, $B$. cheitantha e $B$. splenden) têm demonstrado sua ação hipoglicemiante em animais de laboratório (Pepato, 2002; Lino et al., 2004; Barbosa-Filho et al., 2005). Apesar de utilizados no Brasil há décadas para controlar os níveis de glicose sanguínea em diabéticos (Wakac et al., 1993), ainda são escassos os estudos que comprovem a eficácia e segurança do uso do Mororó em humanos, principalmente quando associado à outro agente hipoglicemiante alopático. Já com relação ao Sabonete de Alecrim (Lippia sidoides Cham), Fernandes Filho et al. (1998) demonstrou sua atividade anti-séptica contra os microorganismos da placa bacteriana em humanos.

\section{CONSIDERAÇÕES FINAIS}

Algumas limitações podem ser notadas no presente estudo. A principal delas é a escassez de produção de alguns fitoterápicos durante o período de coleta dos dados, o que pode ter mascarado nossos dados de prevalência e limitado nossas conclusões sobre a dimensão do uso de fitoterápicos nas UBASF de Maracanaú. A despeito de nossas limitações, podemos sugerir que existe um cenário favorável ao Programa Farmácias Vivas desenvolvido nesse município, uma vez que os fitoterápicos vêm sendo produzidos ao longo de anos, suprindo a lacuna deixada pela escassez de medicamentos alopáticos na rede pública. No entanto, estudos posteriores são necessários para a garantia do controle de qualidade, da eficácia e segurança dos fitoterápicos desenvolvidos, conforme exigências da legislação vigente no país. Tais estudos poderiam ser realizados através de parcerias entre a rede pública de saúde e as universidades públicas locais, de modo a otimizar de uma vez por todas a produção e utilização dos fitoterápicos no sistema municipal de saúde de Maracanaú, bem como nos demais municípios que desenvolvem um programa de fitoterapia na atenção primária.

\section{AGRADECIMENTOS}

Agradecemos à farmacêutica chefe do Setor de Assistência Farmacêutica de Maracanaú, Maria Marlene Freitas Andrade, e aos profissionais de saúde e pacientes das UBASF, pelo apoio incondicional ao estudo, bem como à Fundação Cearense de Apoio à Pesquisa (FUNCAP), pelo suporte financeiro.

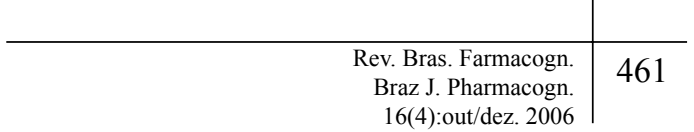




\section{REFERÊNCIAS}

Andrade MMF 2000. Memento farmacêutico. Maracanaú: Prefeitura Municipal de Maracanaú - Secretaria de Saúde, Setor de Assistência Farmacêutica, 24p.

Astin JA 1998. Why patient use alternative medicine: results of a national study. JAMA 279: 1548-1553.

Barbosa-Filho JM, Vasconcelos THC, Alencar AA, Batista LM, Oliveira RAG, Guedes DN, Falcão HS, Moura MD, Diniz MFFM, Modesto-Filho J 2005. Plants and their active constituents from South, Central, and North America with hypoglycemic activity. Rev Bras Farmacogn 15: 392-413.

Bertoldi AD, Barros AJD, Hallal PC, Lima RC 2004. Utilização de medicamentos em adultos: prevalência e determinantes individuais. Rev Saúde Pública 38: 228-238.

Brasil 2004a. Ministério da Saúde. Agência Nacional de Vigilância Sanitária (ANVISA). Resolução - RDC $n^{\circ} 48$ de 16/03/2004 - Dispõe sobre o registro de medicamentos fitoterápicos. Diário Oficial da União, Brasília, DF, 18 de março.

Brasil 2004b. Ministério da Saúde. Agência Nacional de Vigilância Sanitária (ANVISA). Resolução - RE n ${ }^{\circ} 89$ de 16/03/2004. Determina a publicação da "Lista de registro simplificado de fitoterápicos". Diário Oficial da União, Brasília, DF, 18 de março.

Cosendey MAE, Bermudez JAZ, Reis ALA, Silva HF, Oliveira MA, Luiza VL 2000. Assistência farmacêutica na atenção básica de saúde: a experiência de três estados brasileiros. Cad Saúde Pública 16: 171-182.

Dias da Costa JS, Facchini LA 1997. Utilização de serviços ambulatoriais em Pelotas: onde a população consulta e com que freqüência. Rev Saúde Publica 31: 360-369.

Fernandes Filho ES, Morais SM, Fonseca SGC, Mota OML 1998. Preparação e avaliação clínica de um antiséptico bucal à base do óleo essencial da planta medicinal Lippia sidoides Cham (Alecrim pimenta). Rev ABO Nac 6: 323-325.

Harnack LJ, Rydell SA, Stang J 2001. Prevalence of use of herbal products by adults in the Minneapolis/St Paul, Minn, metropolitan area. Mayo Clin Proc 76: 688694.

Leite SN 2000. Além da medicação: a contribuição da fitoterapia para a saúde pública. São Paulo, 114p. Dissertação de Mestrado - Faculdade de Saúde Pública, Universidade de São Paulo.

Lino CS, Diógenes JP, Pereira BA, Faria RA, Andrade Neto M, Alves RS, Queiroz MG, Sousa FC, Viana GS 2004. Antidiabetic activity of Bauhinia forficata extracts in alloxan-diabetic rats. Biol Pharm Bull 27: 125-127

Malta JR, A.Diniz, MFFM, Oliveira RAG 1999. Das plantas medicinais aos fitoterápicos - Abordagem multidisciplinar. João Pessoa: PET-FARMÁCIA/ CAPES/UFPB.

Matos FJA 1998. Farmácias vivas. Fortaleza: Editora da Universidade Federal do Ceará.

Michilis E 2004. Diagnóstico situacional dos serviços de fitoterapia no Estado do Rio de Janeiro. Rev Bras Farmacogn 14 (Supl. 1): 16-19.

Negreiros MSC 2002. Uso do medicamento fitoterápico na atenção primaria do município de Pereiro-Ce. Fortaleza, 98p. Monografia - Faculdade de Saúde Pública, Universidade Estadual do Ceara.
Ogava SEN, Pinto MTC, Kikuchi T, Menegueti VAF, Martins DBC, Coelho SAD, Marques MJNJ, Virmond JCS, Monteschio P, D’aquino M, Marques LC 2003. Implantação do programa de fitoterapia "Verde Vida" na secretaria de saúde de Maringá (2000-2003). Rev Bras Farmacogn 13 (Supl.1): 58-62.

Pepato MT, Keller EH, Baviera AM, Kettelhut IC, Vendramini RC, Brunetti IL 2002. Anti-diabetic activity of Bauhinia forficata decoction in streptozotocin-diabetic rats. J Ethnopharmacol 81: 191-197.

Ribeiro AQ, Leite JPV, Dantas-Barros AM 2005. Perfil de utilização de fitoterápicos em farmácias comunitárias de Belo Horizonte sob a influência da legislação nacional. Rev Bras Farmacogn 15: 65-70.

Sanfélix GJ, Palop LV, Pereiró BI, Martínez-Mir I 1999. Influencia del sexo del paciente en la calidad de los medicamentos consumidos. Aten Primaria 30: 163170.

Sanfélix GJ, Larrea VP, Gomis RE, Martínez-Mir I 2001. Consumo de hierbas y medicamentos. Aten Primaria 28: 311-314.

Silva MIG 2003. Utilização de fitoterápicos nas unidades básicas de atenção à saúde da família, no município de Maracanaú-Ceará. Fortaleza, 147p. Dissertação de Mestrado - Faculdade de Farmácia, Odontologia e Enfermagem, Universidade Federal do Ceará.

Silva MIG, Sousa FCF, Gondim APS 2005. Herbal therapy in primary health care in Maracanaú, Ceará, Brazil. Ann Pharmacother 39: 1336-1341.

Silva T, Schenkel EP, Mengue SS 2000. Nível de informação a respeito de medicamentos prescritos a pacientes ambulatoriais de hospital universitário. Cad Saúde Pública 16: 449-455.

Vianna ALD, Dal Poz MR 1998. A reforma do sistema de saúde no Brasil e o Programa Saúde da Família. Rev Saúde Coletiva 8: 11-48.

Viana AL, Heimann LS, De Lima LD, De Oliveira RG, Rodrigues SH 2002. Significant changes in the health system decentralization process in Brazil. Cad Saude Pública 18(Supl.): 139-151.

Waack H, Mercedes G, Flores J, Carmen E 1993. Plantas medicinales en atención primaria en salud. Lima, 127p. Disertación del Mestrado - Universidad Nacional Mayor de San Marcos. 